\title{
The Aegean sea marine security decision support system
}

\author{
L. Perivoliotis, G. Krokos, K. Nittis, and G. Korres \\ Hellenic Center for Marine Research, 46,7 Km Athens-Sounion Road, Anavissos, 19013, Greece
}

Received: 1 March 2011 - Published in Ocean Sci. Discuss.: 4 May 2011

Revised: 17 August 2011 - Accepted: 27 September 2011 - Published: 24 October 2011

\begin{abstract}
As part of the integrated ECOOP (European Coastal Sea Operational observing and Forecasting System) project, HCMR upgraded the already existing standalone Oil Spill Forecasting System for the Aegean Sea, initially developed for the Greek Operational Oceanography System (POSEIDON), into an active element of the European Decision Support System (EuroDeSS). The system is accessible through a user friendly web interface where the case scenarios can be fed into the oil spill drift model component, while the synthetic output contains detailed information about the distribution of oil spill particles and the oil spill budget and it is provided both in text based ECOOP common output format and as a series of sequential graphics. The main development steps that were necessary for this transition were the modification of the forcing input data module in order to allow the import of other system products which are usually provided in standard formats such as NetCDF and the transformation of the model's calculation routines to allow use of current, density and diffusivities data in $z$ instead of sigma coordinates. During the implementation of the Aegean DeSS, the system was used in operational mode in order to support the Greek marine authorities in handling a real accident that took place in North Aegean area. Furthermore, the introduction of common input and output files by all the partners of EuroDeSS extended the system's interoperability thus facilitating data exchanges and comparison experiments.
\end{abstract}

\section{Introduction}

The development of an oil spill forecasting system capable to provide information on demand and support the marine authorities in case of an emergency started with the im-

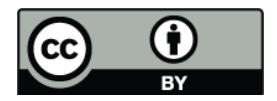

Correspondence to: L. Perivoliotis (lperiv@ homr.gr) plementation of the POSEIDON Operational Oceanography System for the Greek Seas (Soukissian et al., 2000) during the late 90's. At that time, the oil spill weathering and dispersion in the marine environment was calculated by an embedded module of the hydrodynamic forecasting model, using a number of simplified approaches, mainly on the effect of the waves on the oil spreading (Pollani et al., 2001). The first step towards an independent surface pollutant forecasting system was the development of a standalone oil spill model capable to use the high resolution atmospheric, wave and hydrodynamic forecasts that are produced daily by the different forecasting components of the POSEIDON System. The relevant information about the oil spill incident, such as the oil volume spilled into the sea, the date and time of the event, the geographical coordinates and the oil type were fed into the model through a separate input file. Under the above configuration, the system was operated only by specialized scientific personnel who had to gather all the required information about the incident, run the model with the appropriate input and disseminated the results to the end users.

A major upgrade of the system was realized during the research projects ROSES (Real Time Ocean Services for Environment and Security, 2003-2004) and MARCOAST (Marine and Coastal Environmental Information Services, 20052008), funded by the European Space Agency (ESA). These two projects were part of the European GMES (Global Monitoring for Environment and Security) initiative co-funded by the ESA and the European Union (www.gmes.info). The specific projects were part of the GMES Service Elements (GSE) program aiming to deliver decision-support systems for use by the public and the policymakers, with the capability of acquiring, processing, interpreting and distributing information related to environment, risk management and natural resources. In the framework of these two projects, several parts of the oil spill system were modified in order to provide forecasts based on satellite oil spill detection in near real time. This later service was an integration of the oil

Published by Copernicus Publications on behalf of the European Geosciences Union. 
spill detection processes that were applied on satellite based SAR images together with the forecast of oil spill evolution which was provided by the oil spill system (Perivoliotis et al., 2006). The core user of this service was the Marine Environment Protection Division (MEPD) of the Greek Ministry of Mercantile Marine which is the responsible authority for surveillance and response to pollution events in the Greek Seas. The user received near real-time (one hour delay after satellite overpass) synthetic information concerning the oil spill detection and the relevant forecasts in the Aegean Sea through a dedicated web site and was alerted by e-mail/fax/telephone of new information posted to the site (Perivoliotis et al., 2008).

The transformation of the POSEIDON oil spill forecasting module into an operational service during the lifetime of the two projects mentioned above led to the further development of the web interface, which finally resulted to an interactive tool where the user had total control over the model simulation. All the necessary input for the model startup (date and time of the event, location, oil spill volume and type) could be provided by the end user while the produced results were available through the same interface. With the development of this interactive communication tool, the POSEIDON oil spill module became an autonomous decision support system.

The present paper describes the recent development of the POSEIDON oil spill model in order to become an integral component of the European Decision Support System (EuroDeSS) of the ECOOP project. The overall aim of ECOOP (www.ecoop.eu) was to consolidate, integrate and further develop existing European coastal and regional seas operational observing and forecasting systems into an integrated panEuropean system. The transition from a standalone system to an active element of this pan-European system required the Aegean oil spill system to interconnect with other European forecasting systems and use their information to produce its own forecasting results. Furthermore, the input to the system should be provided by a common way as to all others oil spill systems that were part of the ECOOP project while the produced output should also be in a common format in order to be used by all other systems. Under the appropriate additions and modifications, the Aegean oil spill system successfully integrated in the developed European System extending its capabilities to support the marine authorities that have the responsibility of handling emergency situations in the area.

\section{System description}

The Aegean Decision Support System (Aegean DeSS) is based on three different and discrete modules: The background modeling system which provides the necessary information about the atmospheric and marine conditions, the core oil spill model which provides the estimation about the oil spill evolution and the dissemination module where all this synthetic information is available to the end user. In this section, a short description of these modules is presented.

\subsection{Background modeling system}

\subsubsection{The atmospheric model}

The weather forecasting system is based on the SKIRON/Eta model (Kallos et al., 1997), which is a modified version of the Eta/NCEP model and is coupled with a dust cycle prediction model (Nickovic at al., 2001). The system was initially developed between 1998 and 2000 in order to deliver high accuracy weather forecasts forcing the wave, the ocean hydrodynamic, the dispersion and the ecosystem models of the POSEIDON system with surface fluxes of momentum, moisture, heat, radiation (short wave and long wave) and precipitation rates. The system with its nesting capability (Papadopoulos et al., 2002) was operational from 1999 until 2007 and provided $72 \mathrm{~h}$ forecasts in two different model domains and resolutions $\left(1 / 10^{\circ} \times 1 / 10^{\circ}-(10 \mathrm{~km})\right.$ and $1 / 4^{\circ} \times 1 / 4^{\circ}-(25 \mathrm{~km})$ grid increment $)$. The coarser model domain covered an extended area including most of Europe, Mediterranean Sea and North Africa, while with the finer grid increment the model was integrated over the Eastern Mediterranean.

The system was significantly upgraded during 2007 with the addition of the following capabilities: (a) the implementation of the latest non-hydrostatic version of the SKIRON/Eta model (Janjic et al., 2001), (b) the introduction of state-of-the-art parameterisations of all the major phases of the atmospheric dust life such as production, diffusion, advection and removal related to particle size distribution (Kallos et al., 2006), (c) the implementation of a 3-D data assimilation package, the Local Analysis Prediction System (LAPS) in order to produce high resolution analysis. LAPS uses the $1 / 2^{\circ} \times 1 / 2^{\circ}$ GFS/NCEP global analysis to generate 3 -D first guess fields, then integrates all available real-time surface and upper air observations and finally produces a high resolution analysis for the definition of the initial conditions of the atmospheric model. For the boundary conditions the $1 / 2^{\circ} \times 1 / 2^{\circ} \mathrm{GFS} / \mathrm{NCEP}$ global forecasts are used.

The spatial resolution of the upgraded system has been increased to $1 / 20^{\circ} \times 1 / 20^{\circ}(\sim 5 \mathrm{~km})$ while the implementation domain has been extended covering the whole Mediterranean and Black Sea. In the vertical, 50 levels are available up to $25 \mathrm{mb}(\sim 25 \mathrm{~km})$. The system makes use of the high resolution NCEP SST data $\left(1 / 2^{\circ} \times 1 / 2^{\circ}\right)$ and high resolution snow depth and ice cover analysis data.

\subsubsection{The hydrodynamic model}

The Aegean Sea hydrodynamic model is based on the Princeton Ocean model (POM)(Blumberg and Mellor, 1987), and was initially developed as part of the Poseidon Operational Oceanography system (Nittis et al., 2006; Korres et al., 
2002). The model domain covers the geographical area $19.5^{\circ} \mathrm{E}-30^{\circ} \mathrm{E}$ and $30.4^{\circ} \mathrm{N}-41^{\circ} \mathrm{N}$ with a horizontal resolution of $1 / 30^{\circ}$ and $24 \sigma$ layers along the vertical with a logarithmic distribution near the surface and the bottom. The model includes parameterization of fresh water discharge from major Greek rivers (Axios, Aliakmonas, Nestos, Evros) while the inflow/outflow at the Dardanelles is treated with open boundary techniques (Korres et al., 2002). The Aegean Sea model is forced with hourly surface fluxes of momentum, heat and water provided by the Poseidon - ETA high resolution $\left(1 / 20^{\circ}\right.$ regional atmospheric model (Papadopoulos and Katsafados, 2009) issuing forecasts for 5 days ahead. The net shortwave and the downward long-wave radiation terms are provided directly by the atmospheric model while the upward long-wave radiation and the turbulent fluxes are calculated by the hydrodynamic model using its own SST and the relevant atmospheric parameters (air temperature, relative humidity and wind velocity). Boundary conditions at the western and eastern open boundaries of the Aegean Sea hydrodynamic model are provided on a daily basis (daily averaged fields) by the Mediterranean Forecasting System (Tonani et al., 2008). The nesting between the two models involves the zonal/meridional external (barotropic) and internal velocity components, the temperature/salinity profiles and the free surface elevation following the nesting procedures described in Korres and Lascaratos (2003). Additionally, volume conservation constraints between the two models are applied at both open boundaries of the Aegean Sea model.

A multivariate set of observations consisting of $1 / 8^{\circ}$ gridded AVISO SSH data, $1 / 16^{\circ}$ gridded AVHRR SST data (GOS Optimally Interpolated SST), T/S ARGO profiles and temperature profiles from any available XBTs is assimilated into the Aegean Sea forecasting system. The observational data are used on a weekly basis to correct the forecast state of the Aegean model by projecting the forecast error (or innovation) into the state space using the time evolving filter statistics. The assimilation scheme is based on the Singular Evolutive Extended Kalman (SEEK) filter which is an error subspace extended Kalman filter that operates with low-rank error covariance matrices as a way to reduce the prohibitive computational burden of the extended Kalman filter (Pham et al., 1998). The filter is additionally implemented with covariance localization and partial evolution of the correction directions (Korres et al., 2010).

\subsubsection{The sea state model}

The wave forecasting system that is used for the oil spill module is based on the WAM Cycle-4 model code. The WAM model is a third generation wave model, which computes spectra of random short-crested wind-generated waves (WAMDIG, 1988). The WAM model was the first model that solved the complete action density equation, including nonlinear wave - wave interactions. In all, the WAM model code propagates the wave spectrum in time and space taking into account wave generation by the wind, wave shoaling and refraction due to depth and/or currents, quadruplet wave-wave interactions and finally bottom friction and white-capping.

The wave forecasting system mixes different scales of wave phenomenology and variability: the basin and the coastal scale. This is an interesting characteristic of the system which differs from other operational forecasting systems run by national Met-Offices usually developed to pre$\mathrm{dict} /$ hindcast waves in open waters. The system has been developed as part of the POSEIDON II operational system producing daily 5 days sea state forecasts for the Mediterranean and the Aegean Seas. The skill of the system is discussed in Korres et al. (2011) and has been used in the past for the production of a $10 \mathrm{yr}$ Wind and Wave Atlas for the Hellenic Seas (Soukissian et al., 2007).

The wave forecasting system is set-up as a nested configuration with a coarse grid covering the entire Mediterranean Sea at a spatial resolution of $0.1^{\circ} \times 0.1^{\circ}$ and a fine grid nested within the coarse grid. The domain of the fine grid covers the Aegean Sea between $30.4^{\circ} \mathrm{N}$ and $41^{\circ} \mathrm{N}$, and between $19.5^{\circ} \mathrm{E}$ and $30^{\circ} \mathrm{E}$ at a spatial resolution of $1 / 30^{\circ} \times 1 / 30^{\circ}$ resolving the wave spectrum at each grid point in 24 directional and 30 frequency $(0.05 \mathrm{~Hz}>0.79316 \mathrm{~Hz})$ bins. Finally, the system is one-way coupled with the atmospheric forecast model providing 5 days $10 \mathrm{~m}$ wind forecasts at $1 / 20^{\circ} \times 1 / 20^{\circ}$ spatial resolution and hourly frequency.

\subsection{The oil spill model basic features}

The main core of the oil spill model is based on PARCEL model (Pollani et al. 2001), a 3-D numerical model which calculates the pollutant transport (physical movement of the oil in the marine environment) as well as its weathering (transformation of the oil due to interaction with the sea and atmosphere: evaporation, emulsification, sedimentation, beaching). The oil slick is represented as "parcels" that have time dependent chemical and physical characteristics. The 3-D position of each parcel is calculated using advection and diffusion estimates while additional information such as wind and wave conditions and hydrological characteristics are requested for the simulation of the varying physicochemical properties. The oil slick "parcels" are initially given a set of characteristics, among several different classes regarding density, volume and droplet size diameter distribution (Delvigne and Sweeney, 1988). The above characteristics are distributed in each particle in a way that all possible combinations are attained. The evolution of the above characteristics depends on wind and wave conditions as long as hydrological conditions.

The basic processes simulated by the oil-spill model are the evaporation, emulsification, beaching and sedimentation. The method used to characterize the evaporation of the oil has been suggested by Stiver and MacKay (1984) and Stiver et al. (1989). The evaporation routine is performed for each parcel characterized by its initial volume (in moles, deriving 
from mass and density of the oil fraction that represents) and its density. The rate of evaporation depends on the exposure which is a function of time, of mass transfer coefficient (related to the surface kinematics), and of the slick thickness. Evaporation also depends on the $P / R T$ value of the specific alkane. This is also related to the density of the parcel. The evaporated volume is computed permitting the evaluation of the oil slick volume evolution in time. The process influences mainly the lighter fractions of the hydrocarbons and can result to $20-40 \%$ loss of oil in the first few hours.

The numerical approach of the emulsification process that is used in the oil spill model has been proposed by Riemsdijk van Eldik et al. (1986). The process describes the mixing of water in the heavier fractions of the hydrocarbons. The routine is performed each time step for the oil slick fraction with density higher than a critical. The rate of emulsification is affected by the wave and wind conditions characterizing the slick area as well as by temperature and spill characteristics (local thickness, degree of weathering, etc.). The maximum value of the water in oil ratio is 0.7 .

For beaching and sedimentation processes the model uses the Gundlach approach (1987). The sedimentation process describes the trapping of oil particles that reach the sea bottom while the beaching process addresses the trapping of oil along the coast. First the routine sets the coastal boundary indices for particle reflections. If a particle reaches the coast it provides the retention time to the beach and a reflection flag which defines the way that the particle has to go back to the sea. Retention time to the beach assume that the oil remaining to the beach follows an exponential distribution.

\subsection{Dissemination interface}

The development of a user friendly web interface was necessary in order to transform the system from a standalone module into an autonomous decision support system. Through this interface, the end user can setup and submit his own simulation or forecasting scenario and receive the results through the same interface in a comprehensive way.

After providing the required credential information into the welcome screen (http://eurodess.hcmr.gr, Fig. 1) the user can find information and instructions about the use of the system (Fig. 2) and then can access the main setup page where the preparation of model simulation can be realized (Fig. 3). As the Aegean oil drift forecasting system belongs to a European Decision Support System, the interface offers to the user the possibility to submit his own scenario in two ways: (a) by providing the necessary background information for the atmospheric and marine conditions in separate files in common standard format together with all the appropriate initial parameters about the oil spill incident in a common input file or (b) by choosing to use the system's default configuration where the necessary background forecasting results are provided by the POSEIDON System. In this latter case, the user can select the desired point where the oil spill inci-
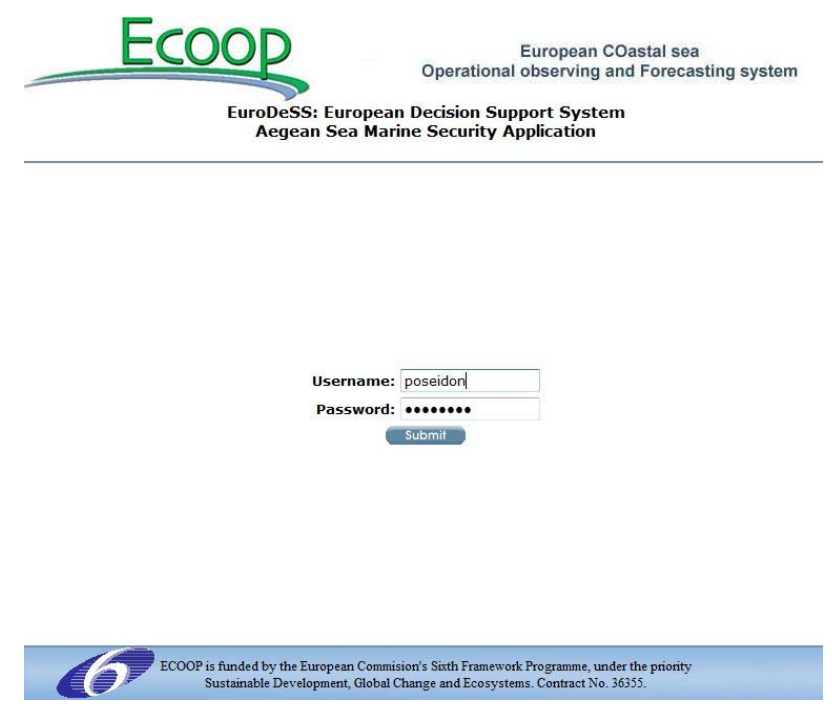

Fig. 1. The first page of the Aegean DeSS (http://eurodess.hcmr.gr) where the user should provide the credential information in order to be able to use the system.

dent is located by clicking the mouse on the provided map or alternatively can type the coordinates in the relevant fields. Then he has to select the date and time of the event as well as the total duration of model integration. The initial date of the run can range between the present time and 10 days ago. This is quite useful in case of an accident where the model can rerun taking into account fresher and updated data from the other forecasting components of the system (atmospheric and marine data). Additional information can be also supplied, if it is known, such as the total oil volume that is disposed to the sea and the time period in which the total amount of the oil discarded at sea (evacuation time). If these two fields are left blank then default values for these two parameters will be used. Finally, the user should enter a valid e-mail address and then click on the submit button. When the submitted job is finished, the user will be notified by e-mail to visit a dynamically created web page where the results of its configured run are hosted. The access to this page needs verification through a username and password which are both included in the e-mail that is sent by the system to the user.

The resulted oil spill evolution is presented in time sequentially graphs (Fig. 4) which can be seen either separately or in animated mode. In each been evaporated, emulsificated, reached the beach or the bottom is also provided. The user can also download through the results web page a file which contains all the produced graphs together with the complete output data, which is provided in the common format agreed between the European institutions for the dissemination of the oil spill model results. 


\section{Transformation from a standalone system to an integrated oil spill module}

As mentioned also in the introduction, one of the main goals of ECOOP project was to establish a European Decision Support System, called EuroDeSS, which will interconnect the relevant systems developed and operated at national level. In the case of oil spill models the harmonization of these individual services was realized by the introduction of standard and common formats for the necessary background information (atmospheric and marine forecasts) as well as with the standardization of the input and output files of the oil spill model. This interconnection extended EuroDeSS interoperability and gave chance to easier data exchanges and comparison experiments.

In order to comply with the above specifications, the oil spill model had to undergo through several modifications which were focused on: (a) the modification of the forcing input data module in order to allow the import of forecasting products from other European systems which are usually provided in standard formats such as NetCDF and (b) the transformation of the model's calculation routines to allow use of current, density and diffusivities data in $z$ instead of sigma coordinates but also to deal with data that are provided on different spatial and temporal resolution.

\subsection{Modifications to allow generic forcing data input}

It was already referenced that the core oil spill model initially developed as a part of the POSEIDON modelling system and therefore its data input module was connected to the customized output of the other parts of the system. In order the interconnection with the relevant systems to be realized, the data input module of the Aegean DeSS should be able to handle data provided in a generic and commonly used format, such as the NetCDF. The direct provision of NetCDF data in the oil spill model required a number of modifications in several model's subroutines in order the correct temporal and spatial projection to be maintained. Furthermore, a major discrepancy that had to be overcome was the fact that the input data through this generic standard format are usually provided in $z$-coordinates while the oil spill model was initially built to use sigma coordinated input. The development of a simple interface where the data was transformed from $z$ to $\sigma$ coordinates before they fed into the model was abandoned since it was introducing erroneous estimations in model's calculations due to the multiple transformations that were applied to the parameters.

The oil spill model's transport calculation routines were transformed to allow use of current, density and diffusivity data directly in $z$ instead of $\sigma$ coordinates. Changes were oriented mainly in handling the vertical structure of the data, where specific considerations related to sigma coordinates had to be redefined. The implementation of these modifications was realized through a continuous comparison between the output of the initial version and the $z$-oriented modified one until the new $z$-oriented version of the core oil spill model to become available.

In order the system to be able to handle input data from different sources, several additional changes were introduced such as:

1. The capability of the appropriate time interpolation when the required input data (atmospheric, wave, oceanographic) are provided in different time resolution.

2. The capability of using a separate file with bathymetric data instead of using the one provided by default. The use of a bathymetry which is compliant with the provided 3-D oceanographic data is expected to significantly reduce expected errors in the vertical data projection.

3. The Stokes drift calculation was improved as suggested by Mellor (Mellor, 2003), using separate calculations for deep and shallow regions which is proved to be more essential for the simulation the near coast behaviour of the waves.

Furthermore, as the oil spill model was tied to the oceanographic one it used the horizontal and vertical diffusion terms as they were provided by the Smagorinsky formula (Smagorinsky, 1963) and the Mellor-Yamada turbulence closure scheme (Mellor and Yamada, 1982) respectively. To overcome this constraint, a new calculation subroutine was implemented into the oil spill model based on Smagorinsky formula for the internal calculation of the horizontal diffusion coefficients, bypassing the need for the external provision of these terms. However, if the vertical diffusivities are not included in the oceanographic input to the model, then this process should be parameterized through the use of constant or biharmonic diffusion coefficients.

\subsection{Common oil spill input and output files}

The final step for the interconnection between the different oil spill systems was the introduction of standard common format for input and output files for all the different partners of the European Decision Support System. The definition of a common way for exchanging information was a challenging task as different types of oil spills were involved with major differences in calculation of oil spill evolution. The outcome of this combined effort between the project's partners was provided as a separate ECOOP deliverable (Paradis et al., 2009). A short description of the finally decided common format for model's input and output is presented hereafter.

The format for both input and output files was decided to be kept in plain text in order to be easier to use in all the different systems. The input file contains basic information for the position of the oil slick, the date and time of the accident, 


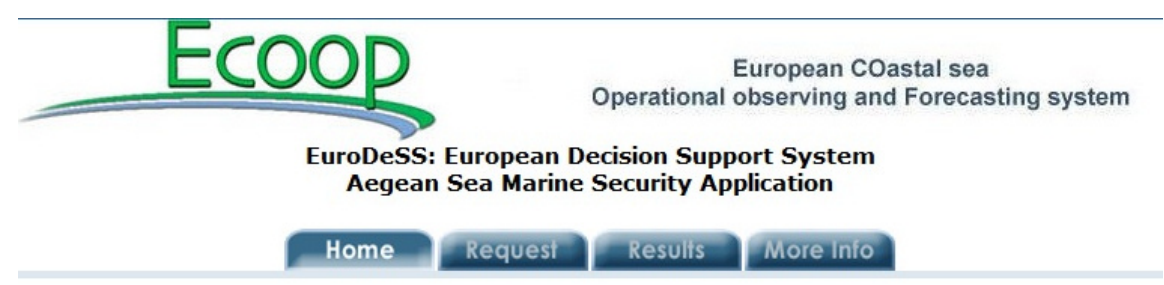

The HCMR oil spill forecasting system (Aegean DeSS) provides forecast information on demand and it is aiming to support the Greek national authorities to handle more efficiently the marine oil spill incidents when they occur.

The Aegean Dess consisted by two parts:

1. The communication interface where the user can setup a number of initial model's parameters in order to create a run that will fit better his needs.

2. The modelling core component which consists by the HCMR oil spill model and its links with the other operational modelling products of POSEIDON system.

The POSEIDON oil spill model has been through the following modeifications in order to become part of EuroDess and to be able to cooperate with a more generic infrastructure of modelled data:

1. The forcing input data module has been transformed to allow import of data in a more generic and standard format, such as NetCDF.

2. The oil spill model's transport calculation routines have been changed to allow use of current, density and diffusivities data in $\mathrm{z}$ instead of sigma coordinates.

3. The input and output interface of the oil spill model has been modified in order to allow the agreed ECOOP common input/output files to be used.

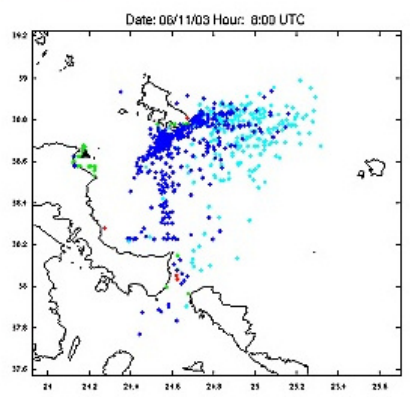

In order to access the application do the following:

1. Click the "Request" tab and submit a request for the Oil Spill Modeling Application. (Be sure to give a valid e-mail address, because you will be notified for the results via e-mail)

2. You will receive by e-mail a username and password in order to have access to the results (after at maximum 10 minutes)

3. Click the "Results" tab and give the username and password provided in the e-mail in the appropiate fields. Click "Submit" and you will have in your screen the results of your request.

Fig. 2. The introductory page of the Aegean DeSS provides general information about the system's use.

the volume spilled into the sea and the total time duration of the spill release. Ocean, atmospheric and wave forcing data is given by the provider's name including the grid size as fraction of degrees. Finally the length of the requested simulation and time interval between two sequential outputs is also required. A sample of the standard input file is shown in Fig. 5.

The output file contains header lines with the information provided by the input file and then follows the oil spill evolution described by the position of the oil particles (parcels) in space during the different output time steps. The provided information consists by the exact time after the accident while the position of each particle is expressed in latitude, longi- tude and depth inside the water column. Furthermore an additional status factor is also provided for each particle which hardy describes its position: 0 (at the bottom), 1 (in the water column), 5 (on sea surface), 10 (beached), 15 (evaporated), 20 (gravity centre of the oil slick), 25 (gravity centre of the head of the oil slick $=$ all particles with size greater than $1100 \mu \mathrm{m}$ and at the sea surface). Any supplementary information that could be possibly produced by each model such as the mass or the viscosity of each particle, the percentage of oil that has been evaporated, emulsified or beached, can be displayed in additional columns. A sample of the standard output file is given in Fig. 6. 

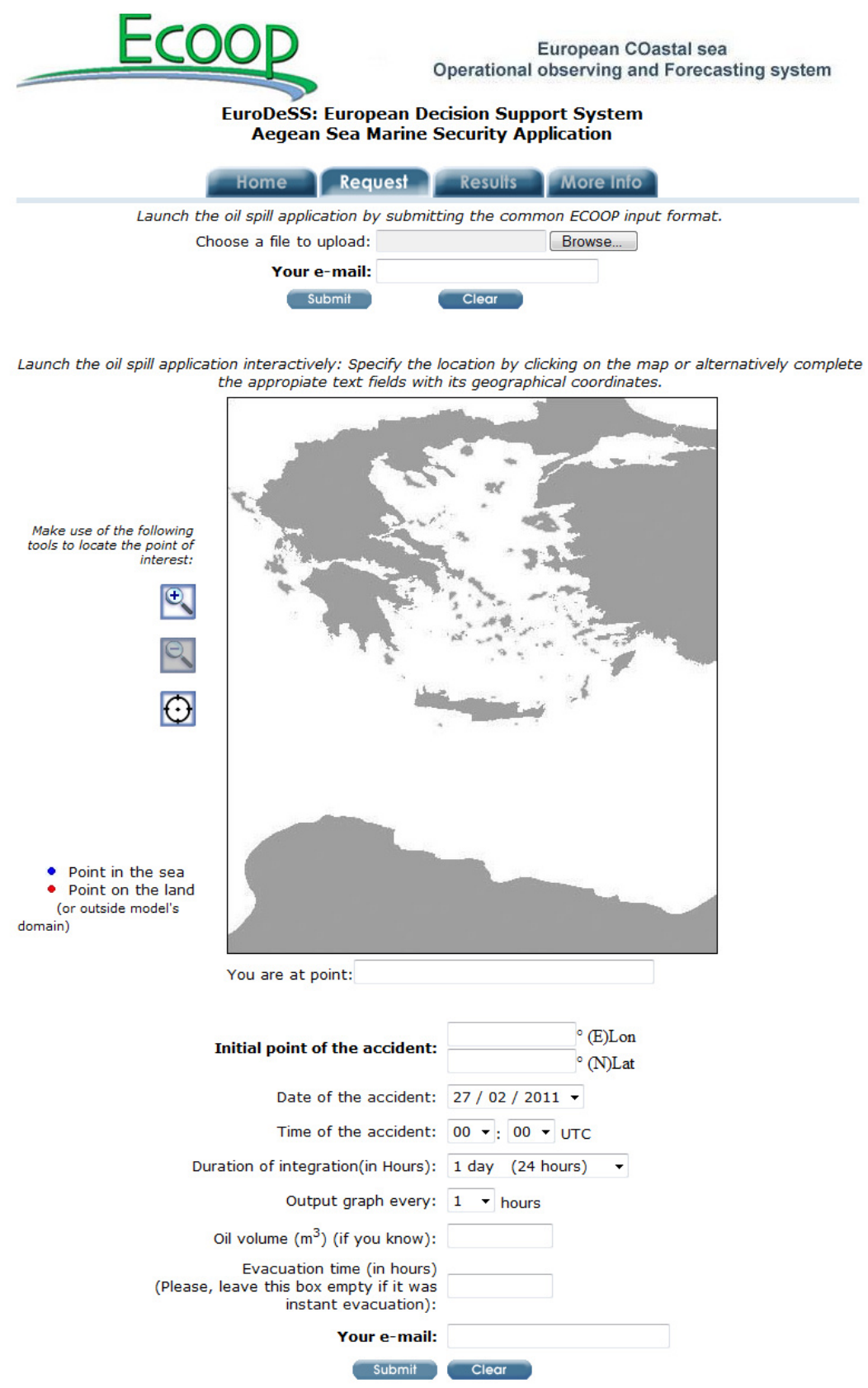

ECOOP is funded by the European Commision's Sixth Framework Programme, under the prionity
Sustainable Development, Global Change and Ecosystems. Contract No. 36355 .

Fig. 3. The user can setup the desired oil spill simulation scenario either by providing all the required information manually or by providing the common input file (upper part of the page).

\section{System operation}

During the ECOOP project implementation, the developed Aegean Decision Support System was used in operational mode to support the responsible Greek marine authorities (Ministry of Mercantile Marine, Marine Environment Pol- lution Division) handling the case of a real accident that took place in North Aegean area at the end of June 2009. Furthermore, the system was also used to generate simulation scenarios for hypothetical accidents in order to exchange data with Meteo France and test the system's interoperability. Both cases are presented hereafter. 


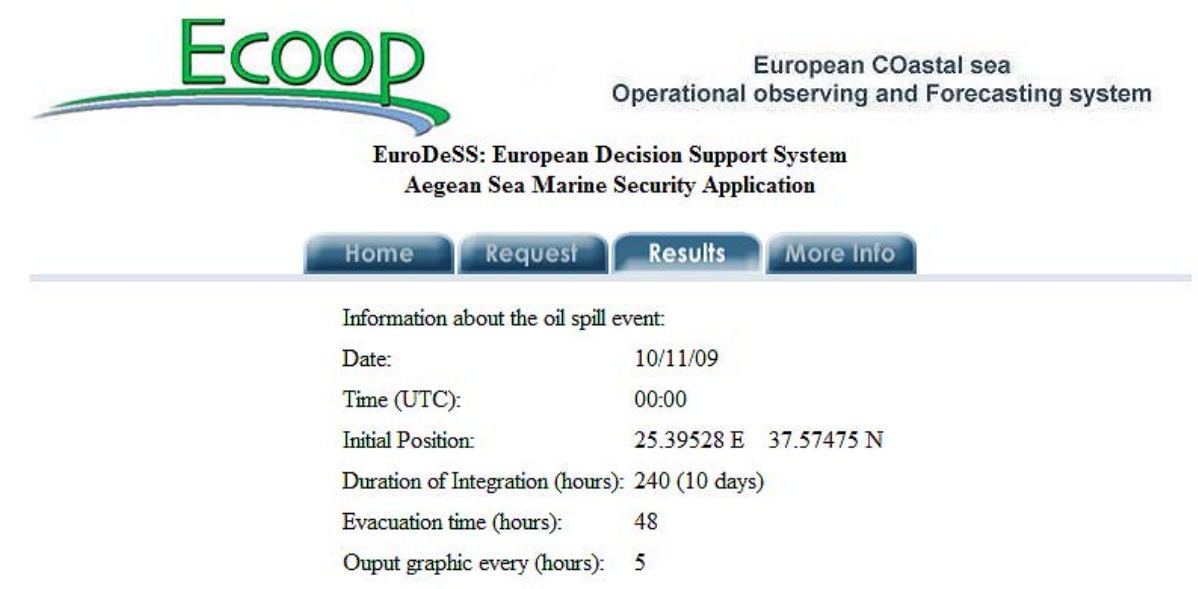

Evap. volume: $17.7 \%$

Emuls. volume: $26.1 \%$

$4.9 \%$ of points on beach
$\Delta$ Initial point of accident - Sea points, $0<$ depth $<=-10 \mathrm{~m}$ Sea points, depth $>-10$ m Sedimentation points - Land points

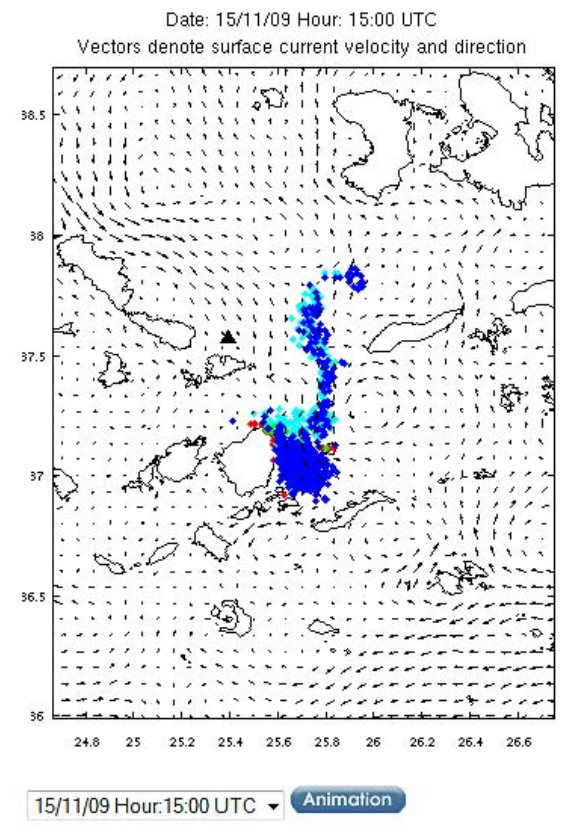

All the graphical outputs with a symmary text are availabe in .zip file. Click here to download the .zip file (size 1.53 MB)

\section{ECOOP is funded by the European Commision's Sixth Framework Programme, under the priority} Sustainable Development, Global Change and Ecosystems. Contract No. 36355.

Fig. 4. The synthetic results output: the oil spill forecast is presented in graphs vs. time together with the animation option. Complementary information about the volume of the oil spill that has been evaporated, emulsificated, reached the beach or the bottom is also provided.

\subsection{Providing support in a real incident}

The accident that alerted the Greek authorities was a collision between two cargo ships in the international waters of the North East Aegean Sea occurred during the night of 27 June 2009. Although no significant amount of oil was initially spilled into the sea, the situation remained critical for several days as the two ships remained stuck after the collision and they were towing slowly towards the Turkish coasts. The Greek authorities requested from the Regional Marine Pollution Emergency Response Centre for the Mediterranean Sea
(REMPEC) to activate the agreement between REMPEC and MOON (Mediterranean Operational Oceanography System) and provide help on preventing and minimizing any possible threat of marine pollution to the Greek territorial waters as well as to the Greek islands, emanating as a result of the collision incident. HCMR as MOON member responded to this request by putting the newly developed Aegean Sea Decision Support System into operational mode. Every day, a complete report with the evolution of the oil spill for the next two days was provided to the Ministry in order to help in 


\section{Input file for oil drift model (event specification + drift request)}

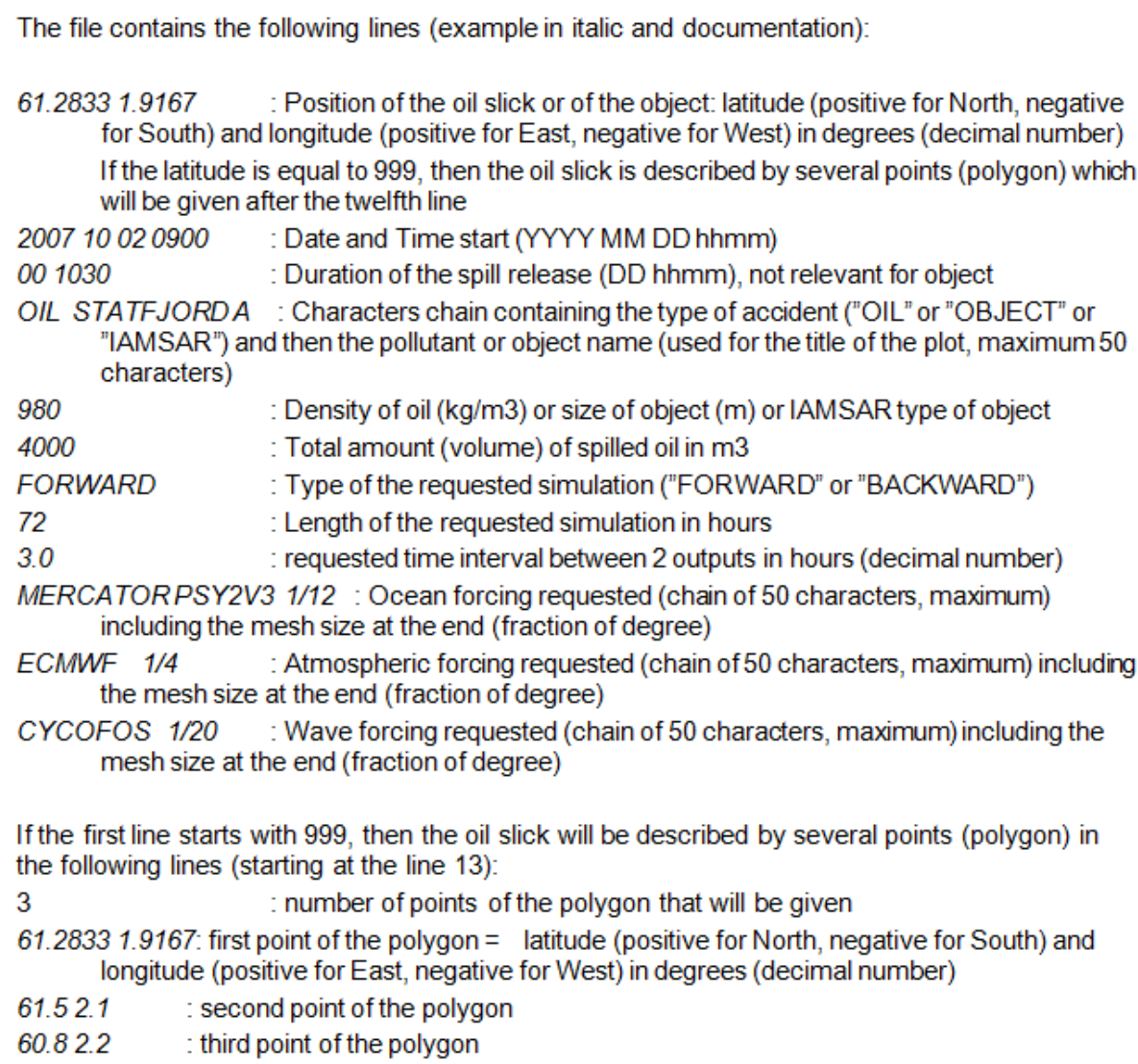

Fig. 5. Sample of the common input file used to provide the necessary information to the oil spill model including explanations for each field.

planning the possible actions in case of major release of oil into the sea. For the production of the daily forecasting information, the POSEIDON atmospheric and marine background data was converted into the common standard NetCDF format and then was fed into the system, as it was required by the previously described Aegean DeSS specifications. Finally, this alerting situation ended without any further complications three days later with the safe towing of the ships to the Turkish coasts. A sample of the oil spill evolution forecast that it was sent to the Greek Ministry is shown on Fig. 7.

\subsection{System interoperability}

The interoperability between two different systems by using the agreed common input and output files has been verified between HMCR and Meteo France through the exchange of data and the comparison of the results. A hypothetical simulation scenario was submitted to the Aegean Oil spill Forecasting System under the following configuration: The area of the accident was located between the islands of Evia and Andros in the Aegean Sea, the time of the accident was set on 14 July 2009, the oil had been continuously released into the sea for the first $24 \mathrm{~h}$ while the oil spill fate in the marine environment was followed for five days. The required background data for the oil spill simulation (oceanic currents, winds and waves) were provided by the high resolution POSEIDON models $\left(1 / 20^{\circ}\right.$ for the atmospheric forcing, $1 / 30^{\circ}$ for the current and wave fields). The original results generated by the system is shown in the Fig. 8 .

The same simulation scenario was reproduced by the French Oil Spill Forecasting system, as both the input and output files of this scenario was sent to Meteo France. The MOTHY oil spill model was used for the drift simulation while the ECMWF winds (1/4 ${ }^{\circ}$ horizontal resolution) were applied as atmospheric forcing. In the French case, three simulations were produced as the flow field was provided by three different sources: (a) climatology, (b) Mercator System (spatial resolution $1 / 12^{\circ}$ and (c) Mediterranean Forecasting System (MFS, spatial resolution $1 / 12^{\circ}$. All the results are plotted together in Fig. 8 with different colors: black for Aegean DeSS (Poseidon), red for ECMWF + climatology, orange for ECMWF+Mercator and green for ECMWF+MFS (Fig. 9). 


\section{Output file for oil drift model}

Example of the common OUTPUT file (Random Case - N. Aegean): 25.70766639 .737

200911010600

000000

OIL NO_NAME

780

30000

FORWARD

48

1

POSEIDON II POM 1/30

POSEIDON II ETA $1 / 20$

POSEIDON II WAM $1 / 30$

Number Time Lat Lon Status Type Mass Depth 1000

$\begin{array}{crrrrrrr}1 & 1.0 & 25.692 & 39.723 & 5 & 0 & 1155.59 & 0.0 \\ 2 & 1.0 & 25.687 & 39.719 & 5 & 0 & 4104.00 & 0.0 \\ 3 & 1.0 & 25.694 & 39.722 & 5 & 0 & 889.99 & 0.0 \\ 4 & 1.0 & 25.686 & 39.717 & 5 & 0 & 4104.00 & 0.0 \\ 5 & 1.0 & 25.684 & 39.721 & 5 & 0 & 325.64 & 0.0 \\ 6 & 1.0 & 25.685 & 39.724 & 5 & 0 & 4104.00 & 0.1 \\ 7 & 1.0 & 25.687 & 39.723 & 5 & 0 & 129.51 & 0.0 \\ 8 & 1.0 & 25.685 & 39.722 & 5 & 0 & 4104.00 & 0.0 \\ 9 & 1.0 & 25.690 & 39.722 & 5 & 0 & 1297.49 & 0.0 \\ 10 & 1.0 & 25.686 & 39.723 & 5 & 0 & 4104.00 & 0.1 \\ 1 & 2.0 & 25.675 & 39.710 & 5 & 0 & 861.31 & 0.0 \\ 2 & 2.0 & 25.666 & 39.702 & 5 & 0 & 4104.00 & 0.0 \\ 3 & 2.0 & 25.675 & 39.708 & 5 & 0 & 325.64 & 0.0 \\ 4 & 2.0 & 25.662 & 39.700 & 5 & 0 & 4104.00 & 0.0 \\ 5 & 2.0 & 25.666 & 39.705 & 5 & 0 & 129.51 & 0.1 \\ 6 & 2.0 & 25.664 & 39.710 & 5 & 0 & 4104.00 & 0.0 \\ 7 & 2.0 & 25.666 & 39.704 & 5 & 0 & 894.21 & 0.0 \\ 8 & 2.0 & 25.667 & 39.707 & 5 & 0 & 4104.00 & 0.0 \\ 9 & 2.0 & 25.668 & 39.707 & 5 & 0 & 931.61 & 0.0 \\ 10 & 2.0 & 25.665 & 39.707 & 5 & 0 & 4104.00 & 0.0\end{array}$

and so on until the end of the drift simulation...

Fig. 6. Sample of the common output file produced by the oil spill model.

It is evident form Fig. 9 that the oil spill evolution pattern that it was produced by Aegean DeSS is significantly different from the French relevant patterns. The mesoscale eddy variability which is known to dominate the Aegean Sea general circulation is expected to be better reproduced by higher resolution models. Thus, the background information fed into the oil spill models is responsible for the observed differences as the lower resolution models used in the French experiment hardly reproduced the Aegean mesoscale dynamics, which is better addressed by the higher resolution POSEIDON models. This experiment reflects the effect of the higher resolution forcing information in the oil spill modeling and not the skill of the oil spill model themselves.

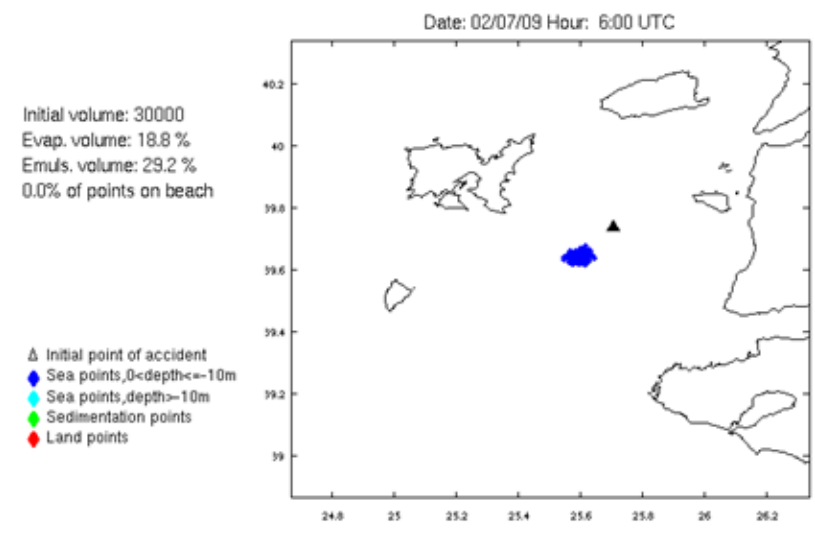

Image 8: Oil spill position on 02/07/09 06:00 GMT

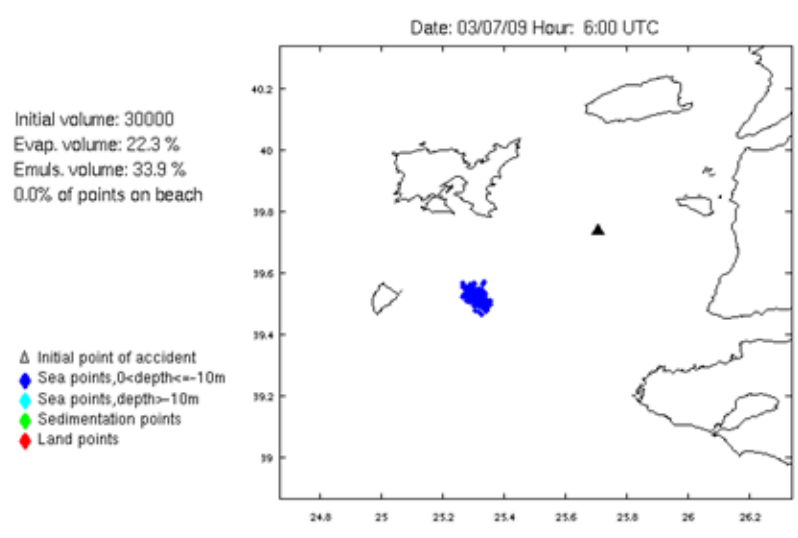

Image 9: Oil spill position on 03/07/09 06:00 GMT

Fig. 7. Sample of the oil spill evolution forecast related to the accident of 27 June 2009 as it sent to the Greek authorities.

\section{Discussion}

In this work the development and implementation of the Aegean Marine Security Decision Support System was presented. As explained above, the development of Aegean DeSS was the last step in the evolution series of the POSEIDON oil spill model that was transformed from a module of the Greek Operational Oceanography infrastructure into a standalone Decision Support System and finally during the ECOOP project into an active element of the European Decision Support System, capable to use and exchange data with relevant systems. As already stated in this work, several changes into the model itself together with the use of common input and output files extend the system's interoperability. 


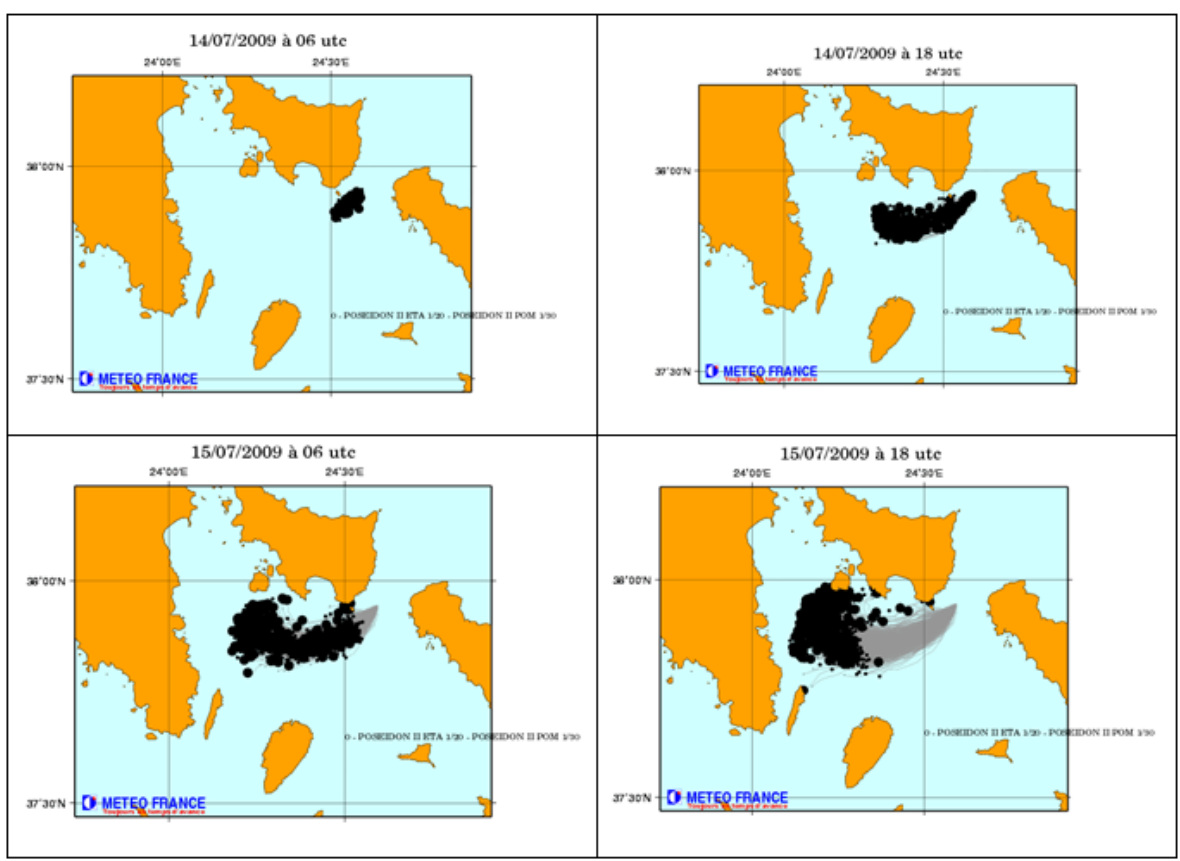

Fig. 8. Simulation of oil spill evolution of a hypothetical accident as computed by Aegean DeSS (event: 14 July $200902: 10 \mathrm{UTC}^{\circ}, 37^{\circ} 57^{\prime} \mathrm{N}-$ $24^{\circ} 36^{\prime} \mathrm{E}$; forcing data provide by POSEIDON models (atmospheric resolution $1 / 20^{\circ}$, oceanographic and waves $1 / 30^{\circ}$ ). Graphics produced by Meteo France, through the use of the common output file provided by HCMR.

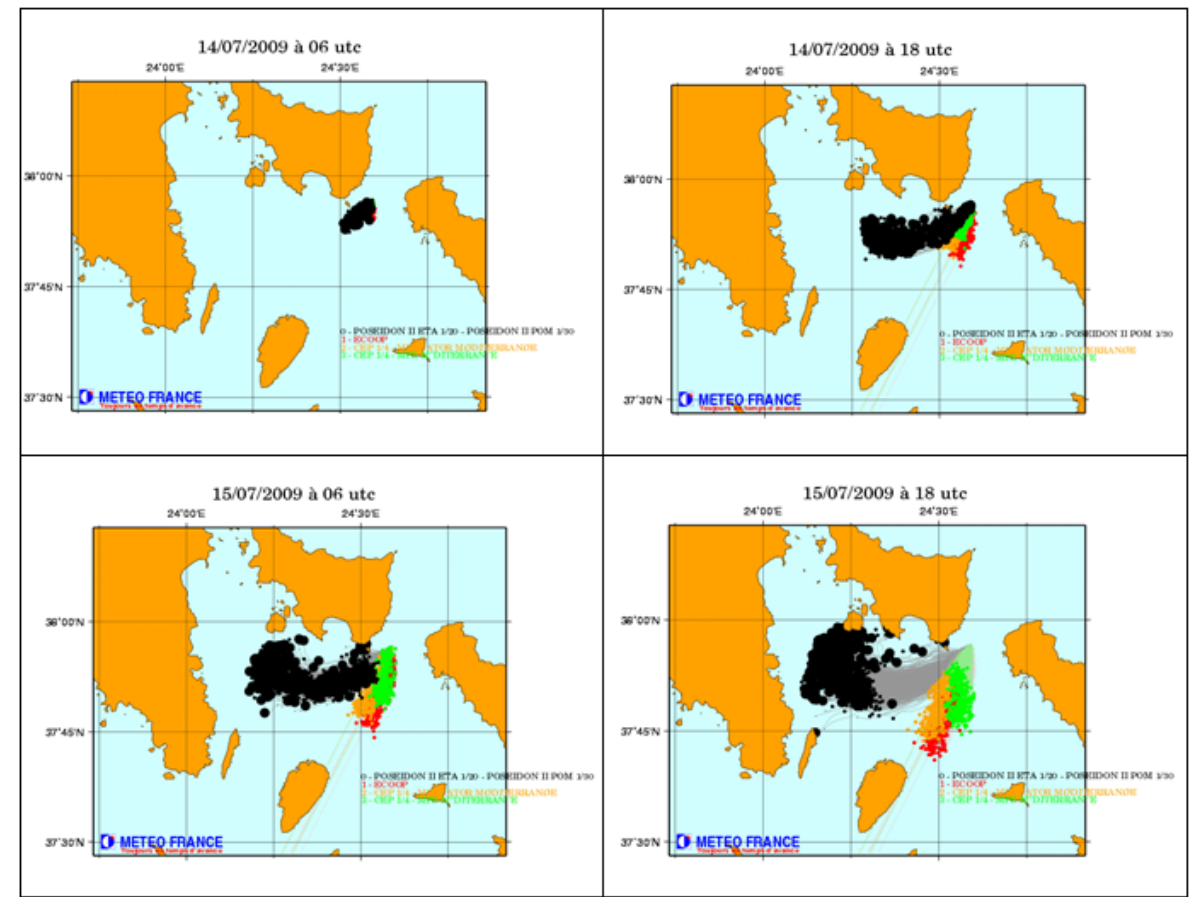

Fig. 9. Simulation of oil spill evolution of the same hypothetical accident as in Fig. 8. The oil slick drift computed by Aegean DeSS is presented in black (forcing data provide by POSEIDON models, atmospheric resolution $1 / 20^{\circ}$, oceanographic and waves $1 / 30^{\circ}$ ). The three computed cases by Meteo France are presented in red, orange and green according to the forcing data: ECMWF $\left(1 / 4^{\circ}\right)+$ climatologic currents (in red); $\operatorname{ECMWF}\left(1 / 4^{\circ}\right)+$ Mercator currents $\left(1 / 12^{\circ}\right)$ (in orange); ECMWF $\left(1 / 4^{\circ}\right)+\operatorname{MFS}$ currents $\left(1 / 12^{\circ}\right)$ (in green). Graphics produced by Meteo France. 
During the project's lifetime, the Aegean DeSS was used to provide support to the Greek end user (Ministry of Mercantile Marine, Marine Environment Pollution Division) in case of a real accident that took place in North Aegean area. Several reports were produced during the period of crisis and delivered to the Greek marine authorities providing detailed information about the possible areas that could be affected if the total amount of the oil spilled into the sea. This frequent reporting provided significant help to the authorities in the precaution actions that had to be taken in order to minimize the effects of a possible pollution. This operational use of the Aegean DeSS and the interaction with the key users during a real incident clearly proved that the usage of the product developed within ECOOP enhanced the ability of the end users to plan the precaution and recovery actions using the risk analysis results that the system is able to provide.

Furthermore, the interconnection between the different oil spill systems that became possible through the use of developed common input and output format provided the opportunity of the direct comparison between the results of different modelling systems that use different input forcing data. This capability, if further developed, could lead to a network of oil spill systems capable to use all the available input data and deliver forecasts in all European seas. Under this configuration, the "best choice" solution would be possible to be applied, i.e. the optimum set of input data would be selected for a specific area and fed into the oil spill model that has been proven to better operate in this area.

Acknowledgements. This work was carried out in the framework of the ECOOP project, funded by the European Commission's Sixth Framework Program, under the priority Sustainable Development, Global Change and Ecosystems - Contract No. 36355.

The authors would like to thank Denis Paradis from Meteo France, for his kind permission in use of the interoperability experiment done by Meteo France.

Edited by: P. Oddo

\section{References}

Blumberg, A. F. and Mellor, G. L.: A description of a three- dimensional coastal ocean circulation model, in: Three-Dimensional Coastal Ocean Circulation Models, Coastal Estuarine Sci., Vol. 4, AGU, Washington DC, 1-16, 1987.

Delvigne, G. A. L. and Sweeney, C. E.: Natural dispersion of oil, Oil Chem. Pollut., 44, 281-310, 1988.

Gundlach, E. R.: Oil holding capacities and removal coefficients for different shoreline types to compute simulate spills in coastal waters, Proc. Oil Spill Conf., 451-457, 1987.

Janjic, Z. I.: The step-mountain eta coordinate model: further developments of the convection, viscous sublayer and turbulence closure schemes, Mon. Weather Rev., 122, 927-945, 1994.

Kallos, G., Nickovic, S., Papadopoulos, A., Jovic, D., Kakaliagou, O., Misirlis, N., Boukas, L., Mimikou, N., Sakellaridis, G., Papageorgiou, J., Anadranistakis, E., and Manousakis,M.: The re- gional weather forecasting system SKIRON: An overview, Proceedings of the International Symposium on Regional Weather Prediction on Parallel Computer Environments, 15-17 October 1997, Athens, Greece, 109-122, 1997.

Korres, G. and Lascaratos, A.: A one-way nested eddy resolving model of the Aegean and Levantine basins: implementation and climatological runs, Ann. Geophys., 21, 205-220, doi:10.5194/angeo-21-205-2003, 2003.

Korres, G., Lascaratos, A., Hatziapostolou, E., and Katsafados, P.: Towards an ocean forecasting system for the Aegean Sea, Global Atmos. Ocean Syst., 8, 191-218, 2002.

Korres, G., Nittis, K., Perivoliotis, L., Tsiaras, K., Papadopoulos, A., Hoteit, I., and Triantafyllou, G.: Forecasting the Aegean Sea hydrodynamics within the POSEIDON-II operational system, J. Operat. Oceanogr., 3, 37-49, 2010.

Korres, G., Papadopoulos, A., Katsafados, P., Ballas, D., Perivoliotis, L., and Nittis, K.: A $2 \mathrm{yr}$ intercomparison of the WAMCycle4 and the WAVEWATCH-III wave models implemented within the Mediterranean Sea, Mediterr. Marine Sci. J., 12, 129152, 2011.

Mellor, G.: The three-dimensional current and surface wave equations, J. Phys. Oceanogr., 33, 1978-1989, 2003.

Mellor, G. L. and Yamada, T.: Development of a turbulence closure model for geophysical fluid problems, Rev. Geophys. Space Phys., 20, 851-875, 1982.

Nittis, K., Perivoliotis, L., Korres, G., Tziavos, C., and Thanos, I.: Operational monitoring and forecasting for marine environmental applications in the Aegean Sea, Environ. Model. Softw., 21, 243-257, 2006.

Papadopoulos, A. and Katsafados, P.: Verification of operational weather forecasts from the POSEIDON system across the Eastern Mediterranean, Nat. Hazards Earth Syst. Sci., 9, 1299-1306, doi:10.5194/nhess-9-1299-2009, 2009.

Papadopoulos, A., Kallos, G., Katsafados, P., and Nickovic, S.: The Poseidon weather forecasting system: an overview, Glob. Atmos. Ocean Syst., 8, 219-237, 2002.

Paradis D., Negre, J., Madrigal, R., Espino, M., Ferrer, L., Fernandes, R., and Perivoliotis, L.: "EuroDeSS Iberian Coast and Western Mediterranean Sea Marine Security Applications: the V1 system and interoperability tests", deliverable no D9.2.4.2 of the ECOOP project (FP6-2005-Global-4), 2009.

Perivoliotis, L., Nittis, K., and Charissi, A.: An integrated service for oil spill detection and forecasting in the marine environment, in: European Operational Oceanography: Present and Future, Publication of the European Communities, Luxembourg, ISBN92-894-9788-2, 381-387, 2006.

Perivoliotis, L., Nittis, K., and Korres, G.: An operational service for oil spill detection and forecasting in the Aegean Sea, Abstracts Book of the 5th EuroGOOS Conference, 20-22 May 2008, Exeter UK, 87, 2008.

Pham, D., Verron, J., and Roubaud, M.-C.: A singular evolutive extended Kalman filter for data assimilation in oceanography, J. Marine Syst., 16, 323-340, 1998.

Pollani, A., Triantafyllou, G., Petihakis, G., Nittis, K., Dounas, K., and Koutitas, C.: The POSEIDON operational tool for the prediction of floating pollutant transport, Marine Pollut. Bull., 43, 270-278, 2001.834-840

Riemsdijk van Eldik, J., Ogilvie, R. J., and Massie, W. W.: MS4: Marine spill simulation software set, Process descriptions, Dept. 
Civil Engineering, Delft Univ. of Technology, Delft, The Netherlands, 74 pp., 1986.

Smagorinsky, J.: General circulation experiments with the primitive equations, Mon. Weather Rev., 91, 99-164, 1963.

Stiver, W. and Mackay, D.: Evaporation rate of spills of hydrocarbons and petroleum mixtures, Environ. Sci. Technol., 18, 834840, 1984.

Stiver, W., Shiu, W., and Mackay, D.: Evaporation times and rates of specific hydrocarbons in oil spills, Environ. Sci. Technol., 23, 101-105, 1989.

Soukissian, T., Chronis, G., and Poseidon Group (Ballas, D., Vlahos, D., Nittis, K., Diamanti, Ch., Perivoliotis, L., Papageorgiou, E., Barbetseas, S., and Mallios, A.): Poseidon: a marine environmental monitoring, forecasting and information system for the Greek Seas, Mediterr. Marine Sci., 1, 71-78, 2000.
Soukissian, T., Hatzinaki, M., Korres, G., Papadopoulos, A., Kallos, G., and Anadranistakis, E.: Wind and wave atlas of the Hellenic Seas, Hellenic Centre for Marine Research Publ., Athens, 300 pp., 2007.

Tonani, M., Pinardi, N., Dobricic, S., Pujol, I., and Fratianni, C.: A high-resolution free-surface model of the Mediterranean Sea, Ocean Sci., 4, 1-14, doi:10.5194/os-4-1-2008, 2008.

WAMDIG: The WAM-Development and Implementation Group, Hasselmann, S., Hasselmann, K., Bauer, E., Bertotti, L., Cardone, C. V., Ewing, J. A., Greenwood, J. A., Guillaume, A., Janssen, P. A. E. M., Komen, G. J., Lionello, P., Reistad, M., and Zambresky, L.: The WAM Model - a third generation ocean wave prediction model, J. Phys. Oceanogr.,18, 1775-1810, 1988. 